\title{
El lugar de lo cómico: algunos desplazamientos en el humor gráfico
}

\section{The place of the comic: some shifts in comics strip}

Federico Reggiani*

\section{RESUMEN}

El humor gráfico contemporáneo presenta formas y temas que ponen en un crisis su ubicación genérica. El presente trabajo examina las características de la tira cómica, la relación entre la tira y el género "chiste" y los desplazamientos que se producen en el ámbito de "lo cómico", desde el cuerpo de la tira cómica hacia la instancia de enunciación. Se analiza en particular la producción de los humoristas argentinos Liniers, Gustavo Sala y Max Aguirre.

Palabras Clave: Comic strip. Cartoon. Discursive Genres. Liniers. Gustavo Sala. Max Aguirre.

ABSTRACT

The contemporary comic strip presents forms and themes that put in a crisis his carácter as a genre. This paper examines the characteristics of the comic strip, the relationship between the strip and gender "joke" and movements that occur in the field of "comic" from the body of the strip to the instance of enunciation. Discussed in particular the production of the Argentine cartoonist Liniers, Gustavo Sala and Max Aguirre.

Keywords: Comic strip. Cartoon. Discursive Genres. Liniers. Gustavo Sala. Max Aguirre.

\section{El recorte}

El particular tipo de producción cultural que conocemos como "humor gráfico" suele ofrecerse al lector a partir un sustrato de evidencia. El "humor gráfico" es algo que se reconoce por ciertas condiciones formales y por su diferencia con el discurso del medio en que se inserta:

\footnotetext{
* Profesor en Letras. Proyecto de Investigación "Estudios y crítica de la historieta argentina”. Escuela de ciencias de la Información, Universidad Nacional de Córdoba, Argentina. http://historietasargentinas.wordpress.com
} 
revistas, diarios, sitios web. La discusión acerca de la definición de "humor gráfico", bizantina como toda discusión sobre definiciones, parece además innecesaria: todo el mundo sabe qué es el humor gráfico y, para colmo, la etiqueta con que lo designamos es casi una definición: es algo que tiene humor y dibujos.

Quisiera proponer, sin embargo, tres tiras de humoristas gráficos argentinos contemporáneos, para proponer una discusión acerca del carácter humorístico de estas producciones, y examinar una serie de desplazamientos del lugar de lo cómico que pueden observarse en buena parte del humor gráfico actual.

\section{Figura 1}

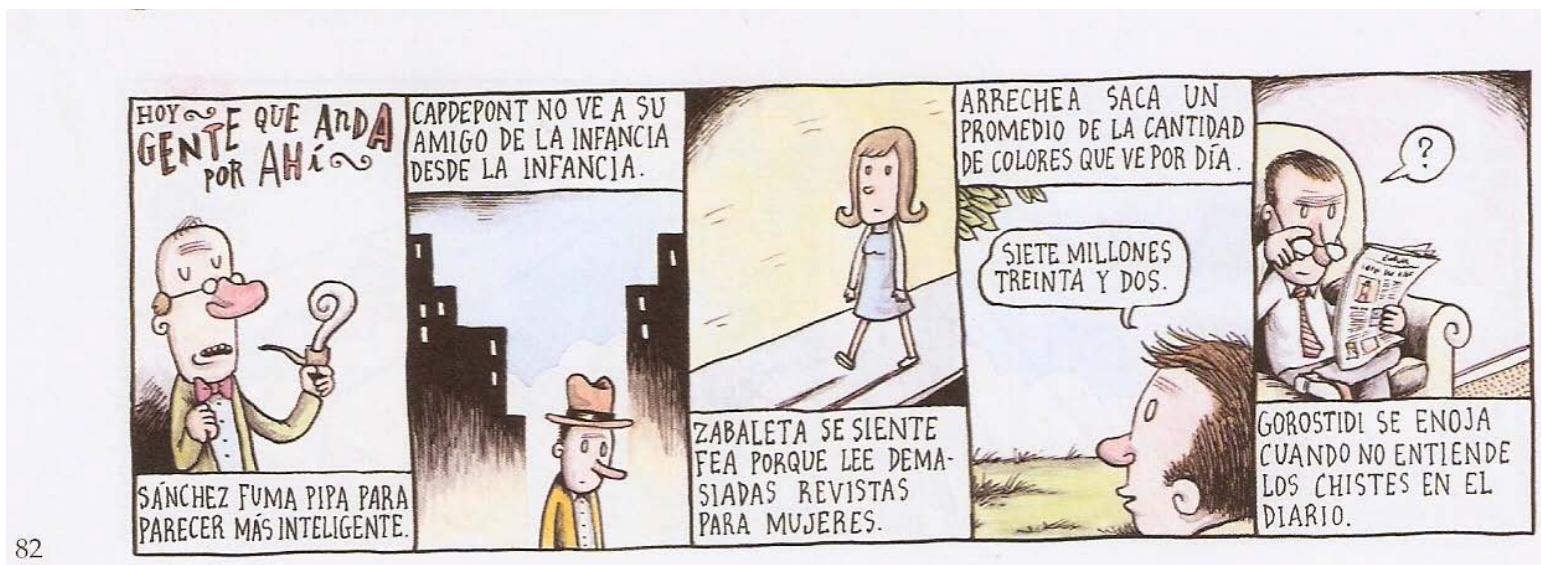

Fonte: LINIERS, 2004, p. 82

Figura 2

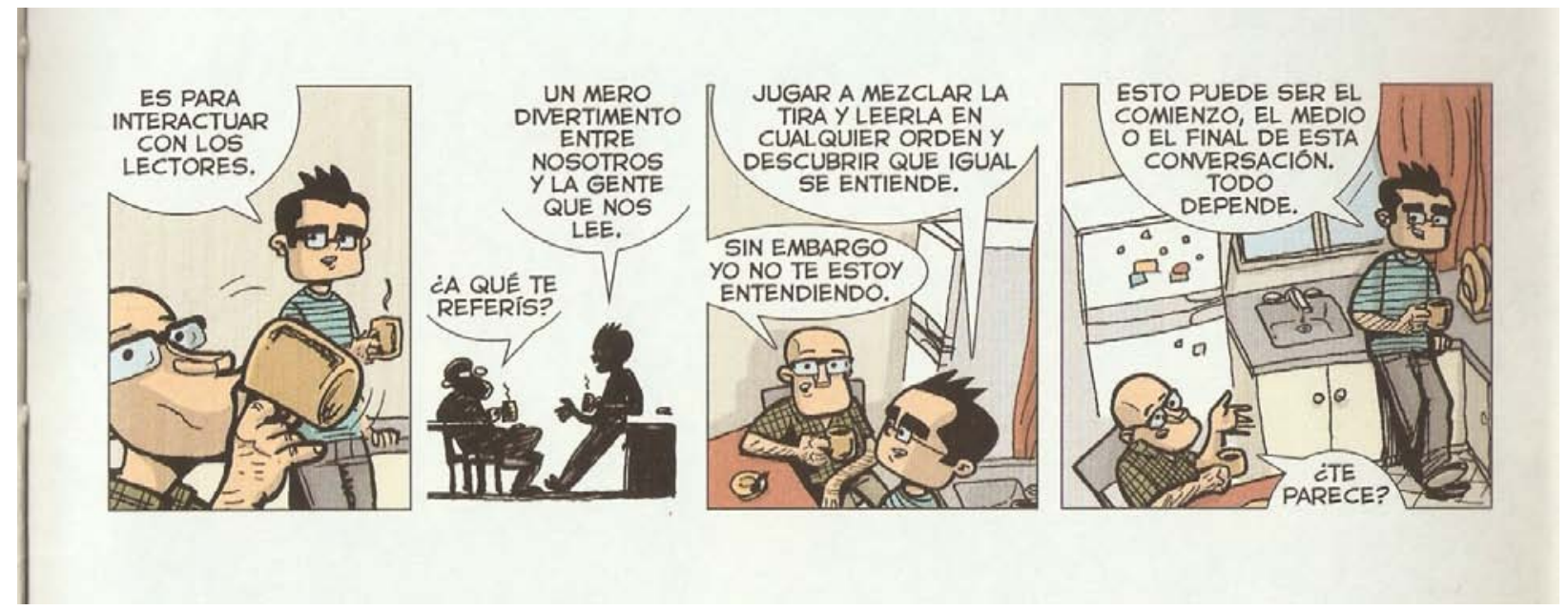

Fonte: AGUIRRE, 2009, p. 23 
Figura 3

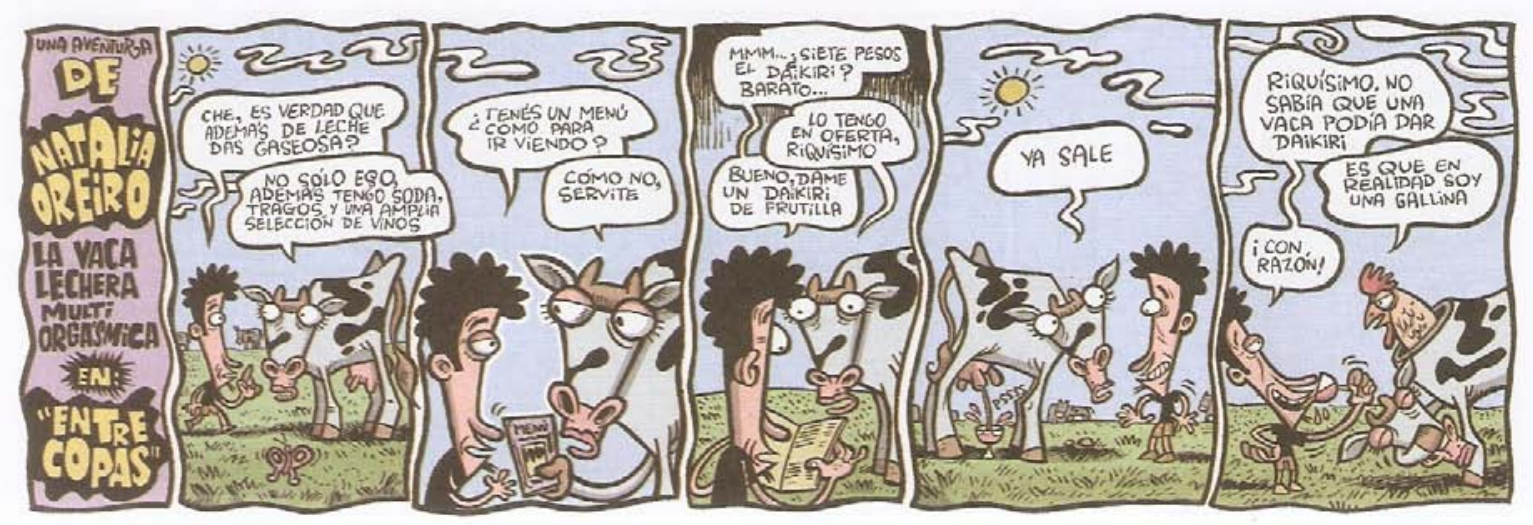

Fonte: SALA, 2008, p. 82

La tira de Liniers ${ }^{1}$ (uno de los primeros ejemplos de una serie que aparece de manera irregular en su Macanudo) propone cinco personajes, caracterizados por una breve descripción de carácter o el relato de un hecho. Nada indica que haya aquí un "chiste", sea cual sea el sentido que se le asigne a la palabra. No sólo no hay elementos que apelen a la risa -salvo, levemente y por razones que examinaré más adelante, la última viñeta- sino que el tono general es más vale melancólico: "Cardepont no ve a su amigo de la infancia desde la infancia".

Si en la tira de Max Aguirre ${ }^{2}$ hay un elemento de comicidad, éste se encuentra desplazado. La tira muestra viñetas que, aunque funcionan como un diálogo continuo, podrían disponerse en cualquier orden o leerse a partir de un cuadro arbitrario sin alterar la comprensión. Como en la tira de Liniers, aquí ha desaparecido un elemento central del humor gráfico, el remate, puesto que la posibilidad de leer la tira en cualquier orden anula la existencia misma de la estructura de preparación y remate clásicos. La comicidad no se propone a partir de los hechos narrados, en el interior de la diégesis, sino en el modo de disponer los elementos; la sonrisa será efecto del reconocimiento de este proceso: el lector debe suspender su lectura del enunciado para percibir que en el nivel de la enunciación se le está haciendo un guiño.

1 Liniers, seudónimo de Ricardo Siri (1973) comenzó a publicar la tira Macanudo en el diario La Nación en el 2002. Desde 1999 hasta ese año había publicado la historieta semanal Bonjour en el Suplemento No! del diario Página/12.

2 Max Aguirre comenzó a publicar su tira Jim, Jam y el otro en el diario La Nación en el año 2007. Antes había realizado una versión autoeditada de la tira, y colaboró con la serie autobiográfica Los Resortes Simbólicos en el blog www.historietasreales.com.ar. 
La tira de $\mathrm{Sala}^{3}$, finalmente, es deliberada y obviamente cómica. No podría pensarse otro objetivo en un discurso cuyo título es "Una aventura de Natalia Oreiro, la vaca lechera multiorgásmica". Pero la gracia no está aquí al final, sino en la acumulación de sinsentidos que se contrapone con la coherencia textual del diálogo. Hay una situación indudablemente cómica, pero se vuelve difícil describir la tira como un chiste y, de hecho, es imposible "contar el chiste" a partir del recuerdo de la tira.

Las tiras seleccionadas no pertenecen a autores underground, ni a ediciones de vanguardia, sino que se publican en diarios de tirada nacional (La Nación, Página 12) y son producciones con una alta visibilidad y una distribución masiva, potenciada además por la circulación en Internet y la recopilación en editoriales con distribución masiva. El objetivo del presente trabajo es reflexionar sobre los cambios que han permitido que un género relativamente estable dentro de lo que podríamos llamar las "narrativas dibujadas" ${ }^{4}$ muestre alteraciones muy radicales en sus presupuestos básicos, al punto de que el elemento "humor" del nombre que lo designa se vea desplazado o incluso llegue a desaparecer. La hipótesis central es que estos humoristas relativamente nuevos para un medio que apuesta regularmente a una muy larga duración de sus producciones- alteran sobre todo el componente enunciativo del género, proponiendo nuevas figuras de autor, nuevos lectores implícitos y nuevas ubicaciones de la instancia de comunicación construida por cada tira. El análisis de la producción de unos pocos autores me permitirá, espero, proponer algunas ideas generales sobre los mecanismos de funcionamiento de la tira de humor.

Para analizar este estado del humor gráfico argentino realicé un recorte y una selección que, como toda construcción de un corpus de lectura, tiene algo de arbitrario, pero que responde a algunas características que considero pertinentes. Los autores seleccionados -Liniers, Max Aguirre y Gustavo Sala-- se incorporaron a medios masivos después de la crisis económica y cultural de 2001 en Argentina, tras una formación y crecimiento en el ámbito de la producción independiente, en fanzines y autoediciones. Este proceso de adquisición casi secreta del oficioopuesto al sistema de aprendizaje con publicación creciente en revistas propio de estados anteriores del campo ${ }^{5}$-- distingue a estos autores de otros como Miguel Rep o Tute, con los que comparten cierta alteración en el uso de lo cómico en sus tiras.

Otro elemento en común entre estos autores es la fuerte circulación de sus historietas en diversos soportes de Internet: versiones digitales de los diarios que los publican; blogs, tanto personales como creados por lectores; fotologs; redes sociales como Facebook y envío privado de las tiras por correo electrónico. La publicación, la circulación y el efecto de cada tira no se limitan por lo tanto a la aparición en el diario y, eventualmente, en libros recopilatorios, sino que se

\footnotetext{
${ }^{3}$ Gustavo Sala comenzó a publicar su tira Bife Angosto en forma semanal en el Suplemento No! del diario Página/12 a partir del 2005.

${ }_{4}^{4}$ Uso un término deliberadamente ambiguo para no entrar en una distinción entre historietas y cartoon de cuadro único, que no es pertinente a efectos de esta discusión.

5 Para una descripción del modo en que se configuró la profesión de historietista en Argentina para los períodos previos a la crisis editorial de la década de 1990, cfr. el capítulo I, en especial los apartados "Aprender practicando: maestros y aprendices" y “Academia de Artes y Oficios" de El Oficio de las viñetas de Laura Vázquez (VAZQUEZ, 2010, p. 43-67)
} 
incorporan a medios con un contrato de lectura impredecible, o por lo menos completamente diverso del que proponen los medios impresos.

La publicación de historietas en Internet merece una justificación adicional, en la medida en que su alcance y trascendencia vuelven cada vez más arbitraria toda limitación a lo impreso. Autores importantes de este período, como Fabián Zalazar o Kioskerman, surgieron también en la primera década del siglo XXI y han alcanzado una circulación y un reconocimiento importantes, sólo que basados casi exclusivamente en la publicación de sus páginas en blogs. La recopilación parcial en libros del material fue un resultado de ese reconocimiento previo. Estos autores han construido sus propios desvíos respecto de la ubicación de lo cómico: Zalazar convierte la narración de breves autobiografías en chistes, Kioskerman los hace desaparecer por completo. Si no los incluyo en el recorte es porque me parece interesante ver cómo llegan ciertos recursos a los medios impresos comerciales, por naturaleza más conservadores en lo que respecta a los desvíos formales aceptables. La publicación de estas nuevas formas en diarios impresos da cuenta de la instalación como estilo de época de ciertos desvíos que son cada vez en mayor medida la norma.

\section{Lo cómico}

Humor, gráfico. Si el el adjetivo puede quedar, por ahora, fuera de la discusión, y es apenas la indicación de que no se trata de humor verbal, la palabra "humor" es el origen de un problema. ¿Es posible una tira o un cuadro que no tengan "humor"? Así parecen demostrarlo en muchas ocasiones los nuevos humoristas. Es necesario, por lo tanto, definir qué se considera humor, o chiste, o comicidad, en el espacio acotado de estas producciones textuales, a efectos de pensar qué es lo efectivamente desplazado. Insisto: en el espacio acotado. No está a mi alcance pero tampoco me parece necesario definir qué es el humor o lo cómico en términos generales, sino el modo en que un funcionamiento determinado de este tipo de texto es reconocido como "humor".

Al respecto, vale comenzar con una discusión que es también la declaración de una deuda. Un trabajo central y ya canónico para entender el humor gráfico es el artículo de Oscar Steimberg "Sobre algunos temas y problemas del análisis del humor gráfico" (STEIMBERG, 2001). En este artículo, Steimberg examina las diversas definiciones de tres categorías emparentadas: comicidad, chiste y humor. A partir de los trabajos de Sigmund Freud, Steimberg define una noción con un mayor grado de generalidad, lo cómico, dentro de la cual se distinguen el humor y el chiste.

Lo cómico surge cuando se quiebra una previsibilidad; irrumpe "cada vez que dos elementos que no suelen formar parte del mismo universo de sentido entran repentinamente en 
contacto" (STEIMBERG, 2005). Dentro de este "reino de lo cómico", y siempre en términos de Freud, es posible distinguir el chiste, "cuando la comicidad está depositada sobre un tercero (STEIMBERG, 2001, p. 2), del humor, cuando se registra "un característico compromiso del sujeto con su propia humorada" (STEIMBERG, 2001, p. 2). Steimberg se concentra sobre todo en la diferencia enunciativa entre chiste y humor. El humor implica un enunciador que pone en crisis su propio yo, que resulta luego salvado por ese distanciamiento que implica la existencia misma del humor, el carácter de juego sobre esa crisis del yo.

Steimberg subraya que esta noción de humor implica la existencia de un enunciador presente, propio de la comunicación oral o de la comunicación con un sujeto marcado por un yo narrador, en la enunciación escrita. El humor gráfico no puede, por su propia naturaleza, proponer un enunciador con esas características, puesto que en el humor gráfico, como en la historieta, hay una "despersonalización" de la imagen de autor. Steimberg (2001, p. 4) marca cuatro razones para esta despersonalización: la condición no presencial; la articulación con otros textos de la publicación en que se inserta; el efecto de enunciación institucional del diario o revista que lo publica; el cotidiano "emplazamiento de género", que presupone un enunciadoroperador con un rol socialmente definido y limitado, que limita el valor de la función "autor" aplicada al humor gráfico. A estas causas podría agregarse el régimen enunciativo propio de la historieta, que no puede construir una instancia única debido a que opera con el montaje de elementos heterogéneos (el dibujo, el diseño, el texto). ${ }^{6}$ A causa de esta "despersonalización", el humor, en sentido freudiano, sería imposible en el humor gráfico, salvo que se den algunas condiciones específicas, debido a que la comicidad del humor gráfico queda necesariamente depositada en un tercero.

La duda que surge de esta argumentación es si la reflexión no está atada a una cuestión de nombres. Como en castellano conocemos al humor gráfico con la etiqueta "humor", pura indiferenciación de sentido, propia de un lenguaje no-técnico, con "chiste" o "comicidad", el análisis se concentra en la posibilidad -o imposibilidad-- del humor (en sentido técnico freudiano) en un relato gráfico. Sin embargo, lo que proponía a una moderada sorpresa del lector en las tiras que utilicé para abrir este trabajo, es el hecho de que nos encontramos con un desplazamiento de lo cómico en el humor gráfico, desplazamiento que puede incluso llegar a su pura desaparición. Examinar la cuestión sólo desde el concepto tećnico de "humor" impide, creo, percibir la novedad de un estilo de humor gráfico que, como subrayé antes, dista de ser marginal y se ha convertido en parte del universo de los medios gráficos más importantes. Porque en estas tiras es todo el "reino de lo cómico" lo que se altera: no siempre hay universos de sentido en lucha, o no es lo más importante de cada entrega o esa lucha no se produce en el cuerpo de ese pequeño relato, en el interior del chiste. Y utilizo chiste no sólo como otro sinónimo habitual para el género que me ocupa, sino también en el sentido de Freud: el chiste como un relato necesariamente en tercera persona, aplicado a otros, los personajes.

\footnotetext{
${ }^{6}$ He desarrollado en diversos artículos el régimen enunciativo propio del lenguaje de la historieta. Cfr., para un resumen Reggiani (2010).
} 
Hablé antes de una discusión, pero también de la declaración de una deuda. Es que las observaciones de Steimberg sobre el humor gráfico son fundamentales para comprender los efectos de este nuevo estilo, que son básicamente efectos enunciativos. Hago la aclaración para justificar porqué, después de anunciar un disenso, sigo en adelante el camino de la glosa.

\section{Los nombres propios}

Una característica muy propia del género "tira cómica" es la presencia de un personaje o una serie de personajes fijos y reconocibles. La cuestión del personaje fijo se asocia hasta tal punto con la idea de tira diaria, humorística o no, que en algunas definiciones de historieta basadas en el reconocimiento de las historietas publicadas en la prensa norteamericana desde fines del siglo XIX-- se considera que la presencia de un protagonista repetido es un rasgo tan importante como la secuencia de viñetas o la presencia de globos ${ }^{7}$. Esta selección de rasgos distintivos para la historieta está más atenta a asegurarle a la historieta norteamericana y al Yellow Kid el lugar de "primer historieta de la historia" que a justificar su pertinencia teórica. Sin embargo, da cuenta de algo indudable: la enorme mayoría de las tiras diarias publicadas utiliza al personaje como eje de organización y coherencia de la serie y, en muchísimos casos, es el personaje el que da título a la tira. Baste recorrer la actualidad de los diarios argentinos para encontrar a La Nelly, Yo, Matías, Diógenes y el Linyera, Batu o Gaturro.

Desde el título mismo, en cambio, las tiras seleccionadas ponen en crisis este eje y renuncian, en diversos grados, a sostener un relato basado en la coherencia (gráfica y de carácter) de un personaje.

En Macanudo ${ }^{8}$, de Liniers, el título hace referencia a un tono general de las historietas y no a un personaje o grupo. En Macanudo hay una gran cantidad de persoanajes, que aparecen con frecuencia irregular y por lo general no forman series continuadas, no se presentan con una historia y una progresión: Enriqueta, Alfio la Bola Troglodita, el Robot Sensible, El Misterioso Hombre de Negro, los pingüinos, los duendes son algunos de los más recurrentes. Pero también hay series temáticas, como "Gente que anda por ahí", "Conceptual incomprensible", "Cosas que a lo mejor le pasaron a Picasso" y tiras individuales. La serie funciona como un marco en el que pueden aparecer producciones de distinto tipo, pertenecientes a géneros diversos.

En el caso de Gustavo Sala y su Bife Angosto también se abandona la costumbre de titular la serie con el nombre de un personaje, pero esa costumbre es retomada en el título de cada tira.

\footnotetext{
${ }^{7}$ Para un resumen de estas posiciones así como para una discusión sobre la terminología, y las características de la "tira cómica" como un formato diferenciado de historieta puede consultarse en el libro de Hernan Martignone y Mariano Prunes Historietas a Diario. (MARTIGNONE, 2008, p. 11-22)

8 Según el Diccionario del Habla de los Argentinos (Academia Argentina de Letras: 2004): "Macanudo: se dice de la persona franca, confiable".
} 
Así, cada entrega se ofrece como "Una aventura de..." un personaje que jamás vuelve a aparecer. "Una aventura de Francisco Bocheton, el creativo eunuco", "Una aventura de Luis María Campos, el tipo al que las drogas le pegan tarde", "Una aventura de Nico Coto, el pibe que cree ver famosos en todos lados".

Esa sucesión de personajes cita un mecanismo clásico del humor gráfico argentino de los años cuarenta y cincuenta del siglo $\mathrm{XX}$, que basaba la comicidad en variaciones sobre la característica única de un personaje: su falsedad, la capacidad de producir mala suerte, la estupidez, la maldad, la gula.. Así se sucedieron en revistas como Rico Tipo o Patoruzito y en periódicos, entre muchos ejemplos, Falluteli, Fúlmine, Bólido, Pochita Morfoni, o Don Fulgencio, "el hombre que no tuvo infancia". Cada uno de los personajes de la Mafalda de Quino responde en cierta medida a esta estructura. El recurso de Sala es la inversión perfecta del mecanismo. Por una parte, contra la repetición opone la aparición súbita y por única vez de cada una de sus criaturas. Contra la comicidad centrada en un rasgo de carácter, el absurdo, puesto que en buena parte de las tiras la característica consignada para el personaje no tiene ninguna relación con el breve relato que le sigue. La excepción a esta regla es una suerte de versión extrema del carácter unidimensional: el único personaje recurrente de Bife Angosto es "José Luis Perales, el fanático de los Redondos". Aquí la comicidad radica en que ante cualquier situación, el personaje diga, tras algunas de viñetas en silencio, "Aguante los Redondos", con un nivel de repetición inimaginable para la tira menos inspirada del pasado.

Casi todos los nombres propios que utiliza Sala para los personajes remiten por evidentes deformaciones o incluso, sin deformación alguna, a personas famosas en diversas actividades, en muchos casos del ambiente del rock, relacionado con el suplemento que publica la serie. (Una mención aparte merecen los personajes que llevan nombres de amigos o colegas del autor: aparecer como personaje en una tira de Sala se ha convertido en una suerte de paradójico honor). Esta apelación a nombres propios reconocibles viola otra característica normalizada en el género "tira cómica": la apelación a la sátira. Como se verá en un próximo apartado, estas producciones desplazan la sátira como operación dominante: el uso del nombre propio en Sala es un claro ejemplo. Salvo en unas pocas excepciones, no se aprecia una burla a la persona real de la que se usa el nombre. Lo cómico no está puesto en la descalificación de un tercero, sino en el choque entre el uso habitual de ese nombre propio y el nuevo sujeto descabellado al que ese nombre pasa a designar. La actriz Natalia Oreiro podrá estar o no feliz por ceder su nombre a una vaca multiorgásmica, pero nadie podría pensar que de alguna manera la tira la alude o satiriza.

La operación con los nombres propios y los personajes que realiza Max Aguirre en su tira Jim, Jam \& el otro es más sutil. Aunque la galería de personajes es muy extensa, su tira se concentra en tres hombres de alrededor de treinta años, a los que, además, representa en ocasiones como niños o como ancianos. Aunque no hay una construcción narrativa novelística, sí hay una caracterización consistente de esos protagonistas, y un uso del personaje como eje de la acción. Y, evidentemente, hay nombres propios en el título. Sin embargo, es en el título donde aparece el primer desvío. Uno de los personajes es "el Otro". Lo que conduce al segundo desvío: 
nunca, en el desarrollo de la tira, sabemos quién es Jim o quién es Jam (y, mucho menos, quién es el Otro). Por otra parte, los personajes, tanto los protagonistas como otros incidentales, no están designados por una cualidad fija (el tonto, el falso, el malvado) sino por detalles menores, que van desde la forma de vestir hasta los regalos que reciben de los Reyes Magos, y que funcionan como indicios de carácter, de clase o de nivel sociocultural pero que no se constituyen nunca como una etiqueta definitiva. El mismo tratamiento puede observarse en los fondos y los personajes incidentales. La función del detalle es la de crear un efecto de realidad que liga la tira, más que al género chiste, al relato realista y a la anécdota cotidiana, que el propio Aguirre frecuentó en Los Resortes simbólicos ${ }^{9}$, la historieta autobiográfica que constituye su otra obra extensa publicada.

Esta decisión de no designar a la tira con el nombre de un personaje y no utilizar el personaje como eje de la tira o, en el caso de Max Aguirre, de jugar con la identificación básica que implica el nombre propio, supone un desplazamiento del principio de coherencia de las tiras hacia el plano de la enunciación. El elemento que hace de cada tira parte de una serie no es la presencia de un personaje, sino el estilo, el trazo y, sobre todo, otro nombre propio, que cobra un protagonismo mucho mayor y que aparece por lo general "del lado de afuera" de la tira: el nombre del autor.

\section{El género "chiste" y el lugar de lo cómico.}

Existe un debate entre lectores y autores en el interior del campo del humor gráfico, relacionado con este "nuevo humor" que es percibido como "no-humor". Insisto: el término "humor" es utilizado en este caso con un sentido vago, indiferenciado de "comicidad". De lo que suele acusarse a estas tiras es de abandonar el deseo de hacer reír y la disciplina de la construcción de un chiste en aras de la reflexión poética o el experimento formal, vistos como formas de la impostura o de la pretensión artística.

Un buen ejemplo de este debate se dio a partir de un texto burlón publicado en el blog del humorista Diego Parés (PARÉS, 2009) ${ }^{10}$

¿Qué pasa con el humor gráfico? ¿Hay algún problema con el humor gráfico? ¿Con las palabras "humor" y "gráfico"? ¿No merecen ser pronunciadas? ¿Ya nadie dice orgulloso: "Yo hago humor gráfico"? ¿Es

\footnotetext{
9 Los resortes simbólicos se publicó a partir de 2006 en el sitio web www.historietasreales.com.ar, y fue parcialmente recopilada en libro.

10 Aunque queda por fuera del recorte propuesto, creo interesante comentar que a partir de 2010, la página de humor del diario La Nación incluye un cuadro de Diego Parés, Humor Petiso. En ese cuadro, Parés se ocupa, de manera evidentemente programática, por recuperar lo que parecía un oficio perdido, el de hacer simples -y muy efectivos-- chistes de un cuadro. Queda claro que ese hiperclasisismo, lejos de contradecir la producción de sus contemporáneos (incluso, de sus compañeros de página Liniers, Tute y Max Aguirre) funciona en el mismo sentido, porque establece un diálogo en el nivel enunciativo con el campo global de la producción de humor contemporánea y previa, campo del cual hay una autoconciencia muy marcada en las decisiones de estilo de cada chiste.
} 
un género menor? ¿Es un oprobio? ¿Es difícil hacer reír? ¿Es fácil hacer reír? ¿Es menos importante hacer reír? ¿Es menos elevado? ¿Es grasa? ¿Es menos artístico? ¿Debería estar prohibido por los canones artísticos de la edad media moderna?

En los comentarios al texto participaron autores como Liniers, Daniel Paz, Kioskerman, Calvi o Podetti. Las oposiciones entre "humor y arte" y la inestabilidad que producen formas asociadas a la comicidad cuando la comicidad parece esfumarse forman el eje de un debate que circula también entre lectores que, como el Gorostidi de la tira de Liniers, "no entienden los chistes".

Por eso es importante examinar cómo funciona esta percibida "desaparición de lo gracioso", del deseo de hacer reír, en las nuevas formas del humor gráfico, y si es que tal desaparición ocurrió realmente.

Es cierto que en muchas tiras, el "chiste" parece haberse esfumado. No tantas como podría pensarse, pero lo suficiente como para volverse un hecho notorio. En Macanudo, sobre todo, abundan las tiras en que sencillamente no hay una intención cómica: no se presenta ese choque de universos que estaría en la base de la irrupción de lo cómico. Las ejemplos más extremos de esta situación se dan en series como "Gente que anda por ahí" (Figura 1) o "Conceptual incomprensible". En la primera, como vimos, se presentan siempre de pequeñas escenas independientes y que nunca tienen continuidad en otras tiras. En la segunda, se ofrecen dibujos o secuencias de dibujos acompañados por un texto, por lo general un verso pareado, sin conexión visible con el contenido gráfico.

\section{Figura 4}

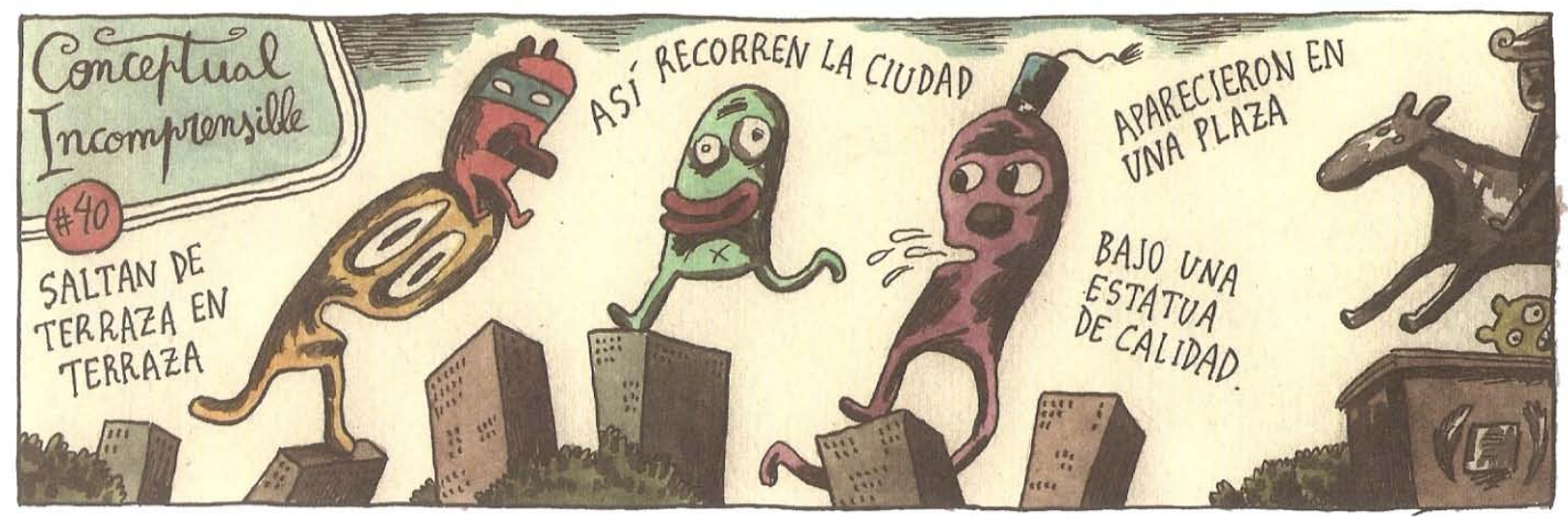

Fonte: LINIERS, 2007, p. 28 
Algo similar ocurre, aunque con menos regularidad, en la tira de Max Aguirre. En el ejemplo de la FIGURA 1 el chiste parece haber desaparecido. En otro ejemplo es posible observar el mecanismo en acción, porque coexisten en la misma tira un chiste (el de los ladrones) con una breve anécdota cuyo efecto humorístico no depende de un remate (y el "choque de universos" correspondiente).

\section{Figura 5}

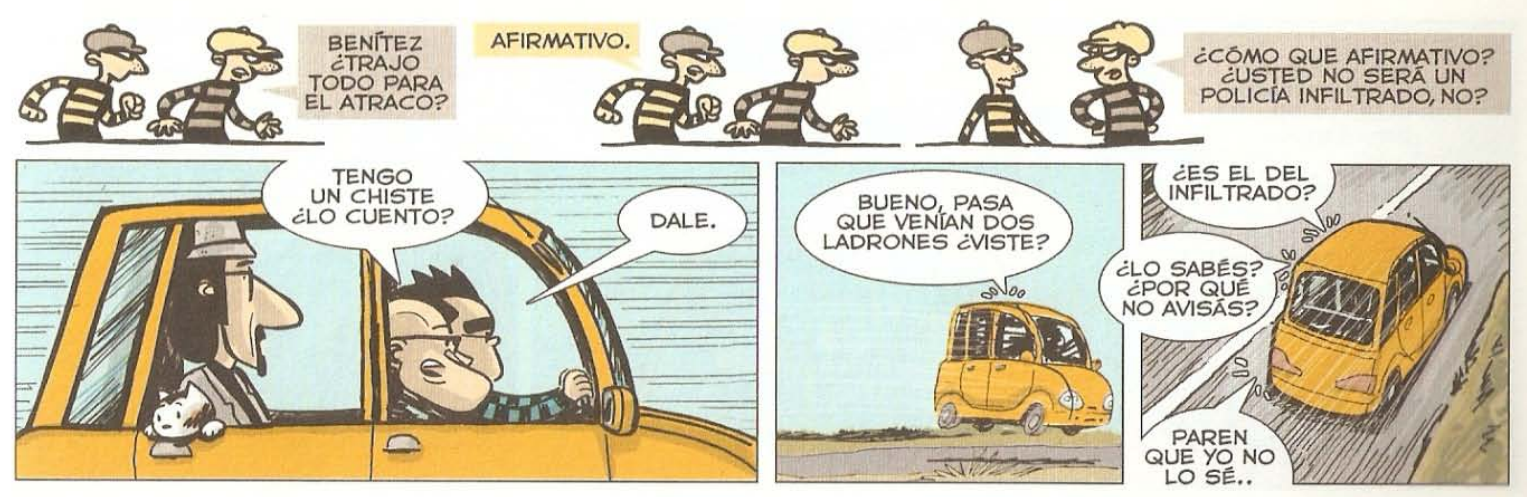

Fonte: AGUIRRE, 2005, p. 71

En el caso de las tiras de Gustavo Sala, sería ridículo decir que lo cómico ha desaparecido: en todos los casos hay una voluntad evidente de causar gracia. Lo que me parece interesante en su caso es el modo en que se desplazan los elementos dedicados a causar gracia, que se de distribuyen de manera muy uniforme en toda la tira, mediante una acumulación abigarrada de notaciones gráficas y textos. El resultado es que resulta muy difícil detectar un chiste: las tiras de Sala son por lo general anécdotas difíciles de reproducir oralmente.

Lo que ocurre en todos estos casos es que se quiebra una relación que parecía indisoluble. El "humor gráfico" deja de ser transposición de lo que, en términos de Bajtin (1999, p. 250), podríamos llamar un "género primario (simple)": el chiste. Es cierto que nada, salvo la etiqueta "humor gráfico" y la costumbre social, establece como necesaria la relación entre ese género, el chiste, y esa particular construcción discursiva compuesta por unos pocos dibujos en secuencia y unos textos intercalados que conocemos como "humor gráfico". Lo que hacen en ocasiones 
Liniers, Max Aguirre y en menor medida Sala es transponer a la secuencia gráfica o gráficotextual otros géneros, primarios o no: el poema, la descripción, la anécdota e, incluso, el puro nonsense o el juego plástico. La dificultad para contar un chiste a partir de una tira de Sala funciona en el mismo sentido. El procedimiento exhibe el hecho de que todos -autores, lectores-confundían un formato de publicación con un género.

El "chiste", ahora, puede estar o no, o puede no ser el elemento principal de la entrega. Se multiplican, aún en tiras que incorporan un chiste convencional, notaciones que alejan el resultado de la funcionalidad de cada elemento. Así encontramos el cuidado plástico de algunas tiras de Liniers, la multiplicación barroca en el grafismo de Sala o los detalles realistas en Max Aguirre.

Ahora bien: si no siempre la tira es transposición al lenguaje gráfico del género primario "chiste": ¿eso implica que desaparece la comicidad? Esto no es tan evidente. Lo que ocurre en muchos casos es que el encuentro entre universos de sentido no se produce como parte de la anécdota, sino en el nivel de la enunciación.

El ejemplo del chiste de los ladrones de Max Aguirre [FIGURA 5] es útil, porque el procedimiento está exhibido en el cuerpo mismo de la tira. El efecto cómico no está en el diálogo entre los amigos que van en auto, sino en el hecho mismo de que ese chiste que se nos escamotea en la parte inferior de la tira sea expuesto (con un grafismo que apela al uso de estereotipos típicos del humor gráfico de etapas anteriores) en la parte superior.

El efecto cómico de muchas tiras de Liniers, en particular las de la serie "Conceptual incomprensible" [FIGURA 4], no está en la tira en sí, sino en una instancia superior: en la pregunta “¿Cómo puede esto ser un chiste?” Este efecto es parecido al que producen algunas tiras de Sala, no sólo por su construcción formal, sino por la elección temática, esa mezcla de escatología y absurdo que es su marca registrada. La pregunta, en su caso, sería “¿cómo pueden publicar esto?".

Lo que puede verse, entonces, no es una desaparición de la comicidad: no necesariamente la "tira cómica" deja de ser cómica. Lo que ocurre es un fenómeno doble: por una parte, el chiste deja de ser el género único en el espacio de la tira. Por otra, esta caída del dominio del chiste en tanto género está relacionada con un cambio del lugar en que el efecto cómico se produce. La comicidad no surge de elementos de distintos universos de sentido que entran en contacto en el interior del enunciado, sino del conflicto entre una instancia de enunciación construida por el medio --la costumbre de lo que debe ser una "tira cómica", el "cotidiano y repetido emplazamiento de género" del que hablaba Steimberg-- que entra en conflicto con la instancia de enunciación que construye la tira concreta que se ofrece al lector. Puede pensarse que los universos que entran en conflicto son diversos "contratos de lectura". (VERÓN, 1985) 


\section{La sátira, el pastiche y el regreso del humor}

El "escándalo enunciativo" que producen estas tiras se relaciona con el funcionamiento de una diferenc planteada por Steimberg: la distinción entre sátira y parodia. (STEIMBERG 2001, p. $6)$.

Steimberg subraya una condición intrínsecamente hipertextual en el humor gráfico:

[...] el cartoon ha sido entendido siempre como discuso sobre discursos; no es en principio concebible que en él haya paisaje, naturaleza muerta o composición abstracta, en la medida en que no es pensable que prime en él la reproducción o producción de lo real en tanto tal. (STEIMBERG 2001, p. 6).

A partir de esta "condición subordinada", Steimberg distingue dos operatorias retóricas opuestas: la sátira y el pastiche. La sátira se basa en una objetivación de enunciados "en la que prima una operación de descalificación o agresión a un tercero (diferenciado del enunciador y enunciatario supuestos por el contrato de lectura". (STEIMBERG, 2001, p. 7). En el pastiche, en cambio, prima el juego con esos enunciados: prima "el régimen lúdico sobre la crítica o el documento, lo que inevitablemente complica o suprime el efecto de confrontación". (STEIMBERG, 2001, p. 7)

El desplazamiento de la sátira al pastiche es visible en el modo en que muchas tiras juegan con la organización de las viñetas, al desarmar la grilla de cuadros sucesivos, utilizan diversos grafismos con función decorativa o realizan citas visuales, desde pinturas famosas hasta clásicos de la historieta y el humor gráfico. Un cierto "escándalo" ante estos juegos, y ésta pérdida del valor dominante de la sátira se explica por una notación de Steimberg: "el pastiche reduce el peso de lo hablado y de lo hablable, característico de la tradición satírica de la caricatura". Efectivamente, al no haber opinión o comentario si no juego, no hay "nada que decir" sobre muchas de las tiras, y su función social (su ubicación en el discurso global del periódico que las alberga) resulta poco definida y por lo tanto motivo de conflicto.

El paso de la sátira al pastiche tiene una consecuencia en el tipo de enunciatario que la tira construye, y en un desplazamiento del lugar de lo cómico. Como se subrayó, quizás en exceso, en el apartado anterior, lo cómico, en tanto choque entre universos de sentido, no aparece en el interior de la tira, sino que se ofrece en el nivel de la enunciación. Lo cómico no surge de algo que le ocurre a los personajes, sino del hecho en sí de que ese discurso sea presentado en el lugar en que tendría que haber "un chiste". La falta de sátira es en sí el chiste. Este desplazamiento produce un enunciatario que, para poder entrar en el juego, debe reconocerse en el juego de citas y en la misma posibilidad de que el juego ocurra. Esta cuestión es fundamental: se presenta la 
necesidad de construir un lector que comparta con el autor esta serie de supuestos sobre lo posible y esta conciencia del juego propio del pastiche. La circulación de estas producción en blogs o redes sociales, con su estela de comentarios y reenvios, fortalece en el plano de los consumos concretos esta construcción textual de la instancia de enunciación.

Quedarían dos observaciones finales. La primera es que por este procedimiento es que el humor gráfico regresa a la posibilidad de incorporar el humor en sentido freudiano. La deuda con el artículo de Steimberg vuelve a ser evidente. En efecto, Steimberg nota que, producidas las despersonalizaciones que impiden construir un "yo" para el humor gráfico, para que sea posible que se produzca humor en sentido freudiano tendrá que construirse una figura diferente de autor:

[...] que sea un autor más que individual [...] el que transite el pasaje entre caída y distanciamiento humorístico. Y esto ocurre cuando la carencia que está en el planteo inicial del gesto de humor aparece asumida por una imagen de autor que se confunde, enunciativamente, con un segmento sociocultural definido, que siempre es estilístico. (STEIMBERG, 2001, p. 6)

En efecto: si lo cómico funciona por el juego y el pastiche, que establece conexiones entre contratos de lectura diversos e incluso incompatibles, depende para su existencia de construir un enunciador que remita a un grupo, el de aquellos capaces de reconocer el nuevo estado de cosas. Cada uno de los autores tratados establece un grupo este tipo. Liniers y Sala apelan a grupos diversos de consumidores culturales contemporáneos, siempre irónicos, heterogéneos y autoconcientes. En el caso de Liniers, con remisiones a la alta cultura; en el caso de Sala, a las zonas más degradadas de la cultura de masas; en ambos, con el supuesto delectores que saben que el espacio de lo decible (a nivel retórico o temático) ha sido drásticamente ampliado. Max Aguirre suma un sistema de detalles de los modos de vida de las clases medias urbanas de Argentina, con su consecuente sistema de (auto)reconocimientos. Construido ese enunciador grupal (ese "segmento sociocultural definido", siempre estilístico, en palabras de Steimberg), se abre la posibilidad de hacer caer la comicidad sobre ese propio enunciador: la posibilidad del humor.

La segunda observación tiene que ver con el posible desarrollo de estas producciones. Si la comicidad está desplazada al espacio de contratos de lectura en pugna, cuando ciertas prácticas se normalizan, se anula el choque entre universos. Un poema incorporado a una tira diaria deja de tener un espacio en el que causar gracia y es, simplemente, un poema. Lo que ocurre cada vez más es que estas producciones dejan en claro que la forma de tira o cuadro gráfico contenido en un medio es un sólo vehículo capaz de proponer los efectos más variados e incorporar los géneros más diversos. Si este estilo se estabiliza y se vuelve habitual, en las frases "tira cómica" y "humor 
gráfico", el adjetivo "cómica" y el sustantivo "humor" dejarán de ser una pura redundancia y pasarán a desginar un género entre otros posibles.

\section{Referencias}

AGUIRRE, Max. Jim, Jam y el Otro. Buenos Aires: Sudamericana, 2009.

BAJTIN, Mijáil. El problema de los géneros discursivos. In: _. Estética de la creación verbal. México: Siglo XXI, 1999.

LINIERS. Macanudo 1. Buenos Aires: Ediciones de la Flor, 2004.

MARTIGNONE, Hernán; PRUNES, Mariano. Historietas a diario: las tiras cómicas argentinas de Mafalda a nuestros días. Buenos Aires: Libraria, 2008.

PARÉS, Diego. Desprecio del humor gráfico. 2009. Disponible en: $<$ http://diegopares.blogspot.com/2009/09/desprecio-del-humor-grafico.html>. Acceso en: 10 Feb. 2011.

REGGIANI, Federico. ¿Quién "dice” una historieta?: historietas y teoría de la enunciación, un resumen In: PRIMER CONGRESO INTERNACIONAL DE HISTORIETAS "VIÑETAS SERIAS, 2010, Buenos Aires. Anales... Buenos Aires: Biblioteca Nacional. Disponible en: <http://www.vinetassueltas.com.ar/congreso/pdf/HistorietaLenguajeyRepresentacion/reggiani.pdf $>$. Acceso en: 10 Feb. 2011.

SALA, Gustavo. Bife Angosto 1. Buenos Aires: Ediciones de la Flor, 2008.

STEIMBERG, Oscar. Sobre algunos temas y problemas del análisis del humor gráfico. Signo y Seña, Buenos Aires, p. 1-11, 2001. Disponible en: $<$ http://www.catedrasteimberg.com.ar/contenido_autores/Sobre\%20el\%20analisis\%20del\%20hu mos\%20grafico.pdf $>$. Acceso en: 10 Feb. 2011.

STEIMBERG, Oscar; TRAVERSA, Oscar. Del arte en lo cómico, de lo cómico en el arte. Figuraciones, Buenos Aires, n. 3, abr. 2005. Disponible en: <www.revistafiguraciones.com.ar >. Acceso en: 10 Feb. 2011.

VÁZQUEZ, Laura. El oficio de las viñetas: la industria de la historieta argentina. Buenos Aires: Paidós, 2010.

VERON, Eliseo. L'analyse du contrat de lectura: une nouvelle méthode pour les études de positionnement des supports presse. In: _ _ _ _ _. Les Medias: experiences, recherches actuelles, aplications. Paris: IREP., 1985. p. 203-230.

Recebido em 30/02/2012

Aprovado em 30/05/2012 
